Article

\title{
Urban Regeneration and the Search for Identity in Historic Cities
}

\author{
Djamel Boussaa
}

Department of Architecture and Urban Planning, College of Engineering, Qatar University, P.O. Box 2713, Doha 999043, Qatar; DjamelB60@qu.edu.qa; Tel.: +974-3363-2925

Received: 3 September 2017; Accepted: 14 December 2017; Published: 26 December 2017

\begin{abstract}
In the face of rapid economic development, population growth, people increasing needs and changing lifestyles, most historic centers in the Gulf have experienced problems in making the necessary adjustment and adaptation to the present needs and changes. This paper examines the role of urban regeneration in revitalizing redundant historic areas and how they can be used to reinforce their cities urban identities. This study is based on the case study approach by focusing on the urban regeneration of Msheireb in old Doha, Qatar. Since the project is not yet completed, this paper will focus on the physical aspects of urban identity rather than its social dimensions. The empirical investigation used a comprehensive fieldwork undertaken through several site visits. This paper argues that one way of rediscovering the urban identity of the city of Doha is to go back to its first roots and try to sustain them in face of the emerging global environments. Through the Msheireb urban regeneration project, this paper explores a new experience in Qatar and the Gulf in creating a new urban identity inspired from the past.
\end{abstract}

Keywords: urban identity; urban regeneration; sustainability; historic centers; Msheireb

\section{Introduction}

Historic urban centers play a major role in enhancing place identity, memory and belonging. In addition, they tend to create an urban identity for the rest of a city and the adjacent districts [1]. Furthermore, Scheffler et al. [2] argued that cultural heritage could be seen as a "soft" value, which provides cities with a unique identity, while competing with other cities to attract global markets.

During the 20th century and onwards, urban development in historic cities has become the backbone of today's world of dynamic environmental, socio-economic and political changes. A number of authors discussed the role of cultural heritage as a main catalyst for economic and cultural development. In this area of investigation, Tweed \& Southerland [3] elucidated the role of cultural heritage in improving lives of people while fulfilling their needs for identity and belonging. In the same line, Evans [4] emphasized the positive impacts of regeneration interventions in historic urban areas, while encouraging many governments to establish culture-led urban strategies.

While the built heritage is important, other values related to memory and identity should not be neglected as they form the essence of a city urban identity. In the following statement, UN Habitat [5] stressed upon the importance of the cultural heritage in present cities; "As a result, planning is being required to preserve and promote cultural heritage, tangible and intangible, of the communities living in cities, since heritage has been recognized to have a role in shaping the city's identity". This statement brings about the role of regenerating cultural heritage as a way to reinforce a city's uniqueness and distinctiveness.

While change is a law of life; in sensitive areas with fragile historic resources, it is important that change should be gradual and not radical to avoid as was named by Jacobs [6] "the sacking of a city". Slow instead of radical change can prevent major displacement and gentrification of local inhabitants 
as stated by Lynch [7] (p. 33) "if change is inevitable, then it should be moderated and controlled so as to prevent violent dislocation and regenerate a maximum of continuity with the past". Therefore, it is important to conserve the built heritage while not undermining the intangible values, to keep a strong continuity with the past.

In the West, during the 1970s, massive urban transformation and renewal projects started to decrease and urban regeneration emerged as an alternative for urban renewal. For instance, the "Amsterdam declaration" [8] established the concept of integrated conservation and praised the positive roles that cultural heritage might play in the contemporary city. Urban regeneration reacts to this concern, by dealing with rational and emotive urban issues such as gentrification of historic districts and centers. This can be done by providing better conditions for the local inhabitants. In addition, revive the tangible and intangible qualities that have disappeared in the mainstream of rapid urbanization and globalization. To maintain a gradual and comprehensive change in cities, it requires from the local stakeholders urgently integrate urban regeneration and identity in their city planning policies agenda.

In the Gulf and since the discovery of oil in the 1950s and 1960s, cities have witnessed dramatic social, cultural and economic changes. These alterations have had direct impact on their historic environments, thus highly threatened their cities' distinctiveness and uniqueness. Globalization trends and the rapid flow of information have played a significant role in changing the built environment; consequently, their cities unique identities based on their past have been dramatically transformed. The staggering construction boom that happened in the Gulf did not leave any room or time for the stakeholders to appreciate their cities cultural heritage [9-11].

In many cities in the Gulf, modernization was given high priority at the ultimate expense of the local cultural heritage. To provide space for new massive redevelopment schemes, a large number of historic districts and areas were entirely erased. This was the easiest and shortest way to implement a tabula raza approach by pulling down historic areas, which sustained for long time a distinctive character of a city. Anything old was considered of little value and was then either demolished or left to decay and disrepair. Moreover, the original inhabitants deserted their houses, which have become later, home for low-income families and single workers. Due to high occupancy rates, in many cases about 100 persons in one house, coupled with dilapidation and lack of maintenance, these historic districts have become "urban slums" in the heart of their cities.

Cities like Dubai, Jeddah and Sharjah have engaged in urban regeneration and renewal programs based on their past during the 1990s. This has resulted in an increasing awareness among the inhabitants of these cities and their competitors of the value of maintaining and reinforcing a city's urban identity. Therefore, urban regeneration can revitalize the area economically while contributing in enhancing the city' urban identity. This paper examines the role of urban regeneration in injecting new hearts in redundant historic areas, in parallel see how they can be reused to reinforce their cities urban identities. This study explores the ongoing urban regeneration of Msheireb project in Doha and since the project is still ongoing, the focus will be on the physical aspects of urban identity.

\section{The Need for Urban Identity}

Post-war modernist planning, based on the Athens Charter principles, separated the city into defined zones with a dominant emphasis on the car, which contributed to create great similarities between cities worldwide. Today the world has become a small village, through global trade, media, space flows, economic connections, free exchange of people, ideas and money. As cities aim to attract global markets through trade and tourism, they struggle to keep their cities distinctive and unique. Today, there is a growing recognition of the need for an individual city's urban identity in an emerging global world.

The concept of urban identity comes often to mind when heritage is discussed. Urban identity is often expressed by the use of a historic distinctive urban form, architectural style, design solutions and ornaments, while utilizing local building materials and construction techniques. Historic environments 
with their buildings have provided a unique visual image of the city before they were drawn up in a sea of global environments. This study believes that, in addition to the construction of new buildings inspired from the past, regenerating historic districts can play a major role in reconstructing the present cities, vanishing urban identities.

The need for a city identity is important as it provides harmony between "constant" and "changing" elements; people and events, which are integrated by a reciprocal link that makes a specific city unique and distinctive [12]. In the same line communities evolve and transform, therefore, conserving certain historic areas is fundamental for retrieving a city's urban identity. In this context, Carta [13] (p. 112) stated "We need to find these invariants and adapt them to contemporary situations and conditions and it is on this heritage of specificity and intrinsic values (history, culture, nature) that one can establish an effective, sustainable local innovation process, which can become a source of a collective identity, a tool of communication between generations and a means of maximizing opportunities".

Relph [14] (p. 147) highlighted the need for place identity, by arguing that: "A deep human need exists for associations with significant places. If we choose to ignore that need and follow the forces of placelessness to continue unchallenged, then the future can only hold an environment in which places simply do not matter. If, on the other hand, we choose to respond to that need and transcend placelessness, then the potential exists for the development of an environment in which places are for man, reflecting and enhancing the variety of human experience". Therefore, it can be concluded that urban identity has become a pressing need in the present city, especially with the emerging globalization trends.

Urban identity has become a very debatable subject that many renowned researchers and urban planners tackled from different angles [15-22]. For instance, Butina-Watson and Bentley [15] (p. 6) stated that "Place identity" is a "set of meanings associated with any particular cultural landscape which any particular person or group of people draws on in the construction of their own personal or social identities".

Urban identity is a blend of the physical heritage, local culture and geographical context, overlaid with perceived remembrances. Furthermore, "City identity is a combination of the aspirations and experiences of the citizens and those who visit. The sense of place and identity is reflected in an understanding of both the wider city region and specific physical places. For each city to find its authentic and distinctive identity in a 'placeless world,' where the same brands occur on every high street, is the challenge" [23] (p. 72).

According to Schulz, sense of place is also seen as the "genius loci of place" referring to the pervading 'spirit of place', in order to enhance, manipulate and enhance our environments [17]. According to Relph, the identity is composed of both the content which refers to people or objects and of the context which consists of the culture and environment, therefore, it is the interaction of both that shapes the urban identity. Moreover, Relph argues that urban identity of a place is consisted of "three inter-related components, each irreducible to the other-physical features or appearance, observable activities and function and meanings or symbols" [14] (p. 61).

In the following statement Rossi [24] unveils the role of collective memories in shaping an identity for a city; "the city itself is the collective memory of its people and like memory it is associated with objects and places. The city is the locus of the collective memory. This relationship between the locus and the citizenry then becomes the city's predominant image, both of architecture and of landscape and as certain artifacts become part of its memory, new ones emerge. In this entirely positive sense great ideas flow through the history of the city and give shape to it".

In summary, one can further examine more definitions of urban identity. To sum up this dynamic concept is defined as 'place-identity', 'placeness', 'character of a place', 'image of a place', 'sense of place' and 'spirituality of place'. These all pertain to urban identity as the concept of 'distinctiveness' and uniqueness, denoting that places are distinguishable from one another [21,22]. Here the word "place" mainly refers to a large-scale environment such as a district, a community or a city. In short, 
urban identity refers to the local character of a place that makes it different and distinctive from other areas.

After discussing the need for urban identity and its various definitions, the main question that needs to be raised here is how to sustain an urban identity for a district or city? In order to preserve or reinforce a local urban identity, a number of designers and architects copy traditional details and insert them in their buildings facades. However, this copy-paste approach is often implemented without fully understanding and exploring the meanings and principles of a local identity [25]. In the same lines, Kim [26] (p. 451) describes many buildings in which designers imitate traditional architectural motifs in the design of governmental buildings, neighborhoods and cities, in many countries in the search for urban identity. While this approach helps respect the existing traditional style, however it is not supported with a sense of place.

A number of scholars raised some aspects related to the physical urban identity. In this context, Lynch [27] listed that uniqueness, congruence, significance, are amongst other aspects that create a sense of place and identity. Alexander [28] claims that wholeness relating to an overall character of a place is developed by continuity and coherence. Along the same lines, Goldsteen and Elliot [29] show how visual and physical principles such as balance, proportion, symmetry, similarity, clarity, compatibility and harmony can enable urban designers to create urban identity. Furthermore, Kelbaugh [30] points out concepts of coherence, continuity, contextuality, imageability, legibility and beauty, all of which contribute to achieving the urban identity of a city.

The different views and opinions makes it difficult to agree on one definition of urban identity. However, there seems to be a consensus on five aspects that can play a major role in reinforcing a local urban identity; continuity, uniqueness, significance, compatibility and cohesiveness [26] (pp. 451-452). These five aspects will form the conceptual framework to analyze the case of Msheireb in old Doha and below a brief description of them.

To attain "continuity" with the past; traditional design elements are often utilized in the design of new buildings. Alexander et al. [31] also suggest that a unique place relies on continuity with the past places and the history of the surrounding physical environment. This suggests that the more historic districts and buildings are conserved the more likely a stronger continuity with the past is achieved.

To realize "uniqueness" of a place, there is a need to differentiate the local place from other places. One way of achieving this is through conservation of the local cultural heritage. Moreover, the new buildings should integrate and respect the local historic built environment. Therefore, conservation of cultural heritage and the development of new built structures respecting the old can help reinforce a uniqueness of a city. To ensure "significance", local monuments and historic districts are being conserved to maintain a sense of local identity. Furthermore, Lynch [27] defines significance of place in terms of the presence of historic events and other symbolic qualities that are manifested in some buildings or districts of the local community.

To reach "compatibility"; new buildings in a historic area should attain a contextual fit with the existing historic built environment and not create any conflict that weaken the local urban identity. In addition, "cohesiveness" can be achieved by creating a homogenous built environment and not fragmented with a myriad of styles. In this way, a coherent urban design pattern would help in strengthening an identity of an area.

To sum up, historic districts can play an active role in sustaining the uniqueness of their cities in the present and future. In dealing with the built heritage, there are various types of interventions in a historic city; repair, preservation, stabilization, restoration, reconstruction, replacement, rehabilitation and regeneration is one of them. The latter, can retrieve some aspects of the past to be a catalyst for reconstructing the lost identities of the present cities [32].

\section{Urban Regeneration and Identity}

As cities have become rapidly homogenized through a process of globalization, what can make them different is the continuity of their local traditions and cultural heritage. Pressures to change 
land-uses is triggered by a number of forces; economic, environmental, socio-cultural or a combination of them all. Urban regeneration has come to represent strategies to change the built environment in order to stimulate economic growth, while not deleting its urban identity [33].

Cities are permanently shifting; land-use changes and districts are redeveloped; the urban areas grow at rapid pace and are often ripe for massive redevelopment projects [6]. To address these issues, urban regeneration projects have been launched to revitalize the declining ancient city centers, old industrial and harbor sites, the old residential areas and diluted historic centers and districts of the cities [34]. Moreover, regeneration is a long-term ambition that involves attempts to rectify problems in obsolete urban areas by improving their economy along with their physical environment, which forms the essence of a city's urban identity.

Roberts [34] describes urban regeneration as "a comprehensive and integrated vision and action, which leads to the resolution of urban problems, which seeks to bring about a lasting improvement in the economic, physical, social and environmental condition of an area that has been subject to change". Moreover, urban regeneration aims to transform the nature of a city or an area by involving the local inhabitants and various stakeholders to attain a number of objectives and targets $[35,36]$. This highlights the need to encourage community participation and bottom up approaches in regenerating areas and districts as a way to reinforce the sense of solidarity and consequently identity.

There is a strong relationship between urban regeneration and identity. Moreover, upgrading the built environment, social fabric and urban spaces within the historical urban structure all contribute towards increasing their adoption as places for public gatherings and exchange. This consequently increases social interaction and cohesion between citizens. As a result, regeneration of historic city centers strives to re-affirm and foster residents' feelings of identity and sense of belonging within the spirit of the past.

Urban regeneration of historic centers contributes largely towards upgrading their environmental, economic and socio-cultural quality to play a major driver for change. Development projects taking place in historic areas can attract both the local and global visitors to discover the main heritage attractions. Furthermore, improving the physical environment, social fabric and urban spaces can increase their adoption as places for social interaction and gatherings. Hence, urban regeneration inclines to reinforce residents' feelings of identity and sense of place within the emerging global environments Norberg [17] (Norberg-Schulz, 1980).

The present Gulf city is the locus of complexity, simultaneity and instability, which creates situations of rapid transformation and transition. These changes are usually driven by economic gain, to the detriment of values related to memory and sense of pride, which has become hybrid, compromised and unrecognizable. This situation is mainly witnessed in the globalizing cities of Dubai, Kuwait, Jeddah and Doha. Their waterfronts exhibit a myriad of "star-architecture" towers, which are completely alien to their local environmental and social contexts.

In dealing with the question of urban identity of the Gulf city and Doha in particular, extensive studies were carried out during the last 20 years [9-11,37-44]. Most of these studies pointed out the necessity to reinforce the gulf cities urban identities based on their past despite the emerging globalization trends. The latter continue to delete what so little remains from the historic districts in Doha and other Gulf cities. The dilemma of sustaining an urban identity based on the past will be examined and discussed in the case of Msheireb. The five aspects of continuity, uniqueness, significance, compatibility and cohesiveness will be explored in the Msheireb regeneration project in Doha.

\section{The City of Doha; a Brief Overview}

Doha is the capital and largest city in Qatar, with over $80 \%$ of the nation's population residing in Doha and its suburbs (Figure 1). It is also the administrative and economic center of the country with a population approaching 2,683,000 persons by the end of November 2017 [45]. Oil was discovered in 1939 but its exploitation was delayed until 1949 because of World War II and the Bahrain embargo. 
Until 1950, Doha was only a small village, consisting of a group of settlements forming a smooth compact strip of five $\mathrm{km}$ along the coast.

Oil exports and payments for offshore rights began in 1949 and marked a turning point in Qatar. In parallel to oil exportation, the year 1949 witnessed the first shipment of cement to Doha as the new modern building material. With the flow of oil revenues and the introduction of new building materials based on cement, during the 60s and 70s, Doha witnessed the launching of large-scale urban development projects. While this rapid urbanization was blessing for the local community by improving their living conditions, it provoked a major threat for their city's urban heritage. Historic districts were swept away, such as old Slata and old Al Ghanem, to provide sites for massive redevelopment projects, thus deleting long chapters of the city's history (Figure 2).

For more than three decades, the cycle of demolition of prominent historic buildings in old Doha did not stop and continued at rapid pace. The great losses of traditional houses had a deep-seated effect on the local community, as it effectively wiped out important chapters of their history and memory. Despite the fact that the historical evolution of these historic districts was in most cases rarely understood, today they are viewed as symbols of community development and as being important in rescuing their city's urban identity.

In parallel to demolition of historic buildings, for the sake of progress and fast modernization, buildings mushroomed, without any respect to the local environmental, physical and social context thus replacing the old structures (Figure 3). However, to keep some ties with the past a number of timid and scattered actions started to appear during the early 1970s. The first rehabilitated building in Qatar was the old Sheikh Mohamed Bin Jassim palace during 1972-1975, to host the new Qatar National Museum as a celebration of the country's independence in 1971 [37].

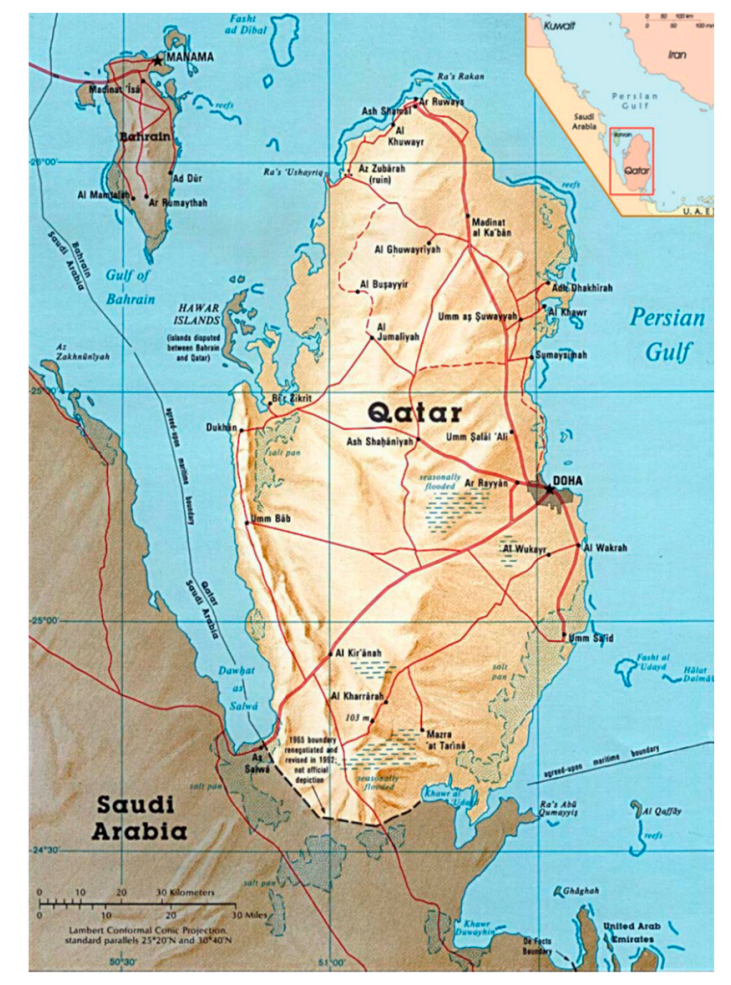

Figure 1. Showing the map of Qatar and the location of Doha on the eastern coast. 


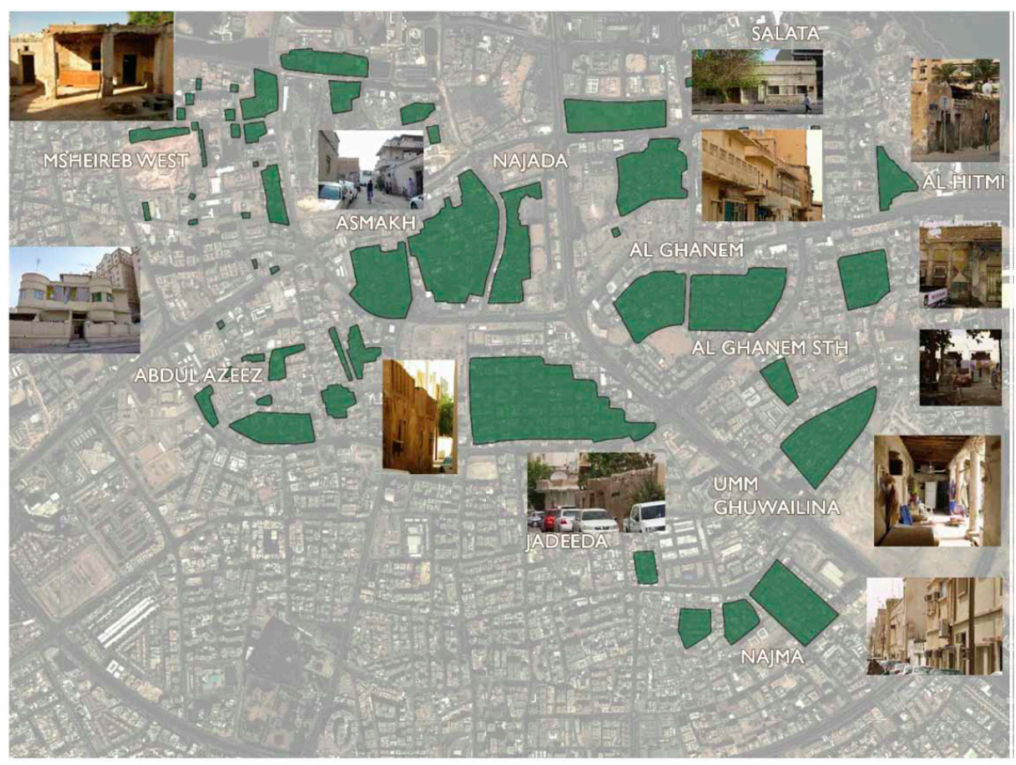

Figure 2. In green; fragments of the remaining historic districts in old Doha (Courtesy of Qatar Museums).

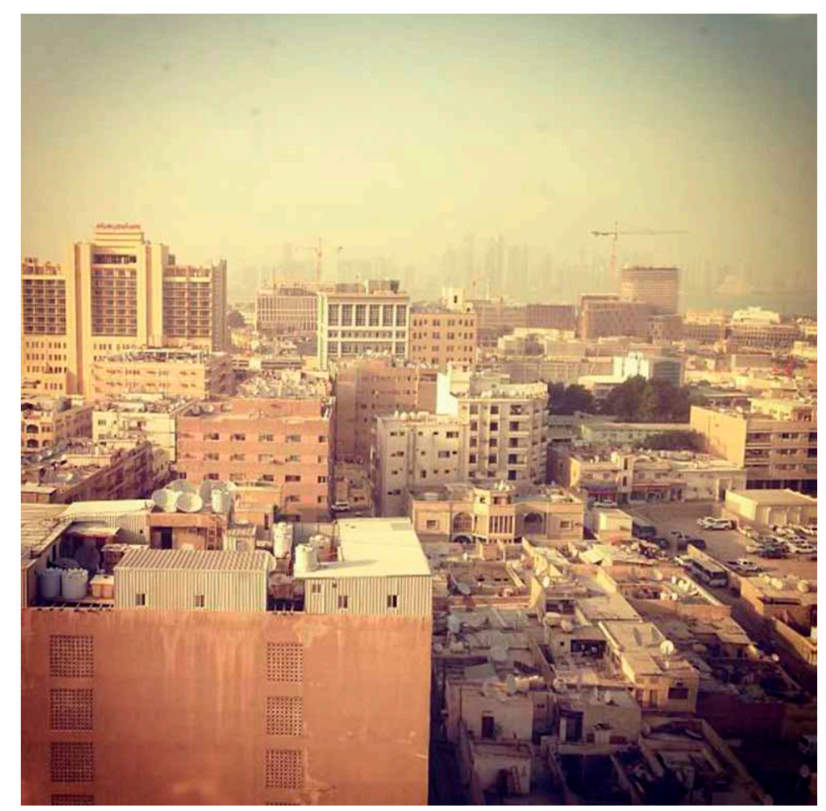

Figure 3. High-rise buildings replacing the low-rise traditional houses in old Doha.

Following this first project, in 1980, the Ministry of Information established the first law relative to conserving the Qatari cultural and archaeological heritage. This is the first reaction of the government towards conservation of cultural heritage. The legislation that protects architectural heritage is defined by "Antiquities Law no. 2 of 1980," which makes it explicit that 'an antiquity is considered to be anything left by civilizations or left by previous generations. This law states that any building built before 1950 is considered as heritage that needs to be conserved. This new law threw the first seeds to conserve what remains of Qatar's cultural heritage and thus offered a new hope to sustain a future for the country's cultural heritage [46].

During the period 1978-1981, land reclamation started in the West bay. The reclaimed land "Al Dafna" prepared a platform for an urban spectacle that exhibits multitude projects of "Star Architecture," hosting the most prominent governmental and commercial buildings. Since then all 
buildings with various international styles can be found in the West bay forming the new global waterfront of the city. These signature buildings vary from high-rise tower blocks, to five star hotels and very attractive shopping malls, which created a hybrid of new identities that ignored the local context. While the west bay was mushrooming with star architecture towers, downtown Doha was ripe for redevelopment and was left to die slowly from decay. These icons and the global towers in the west bay created global identities that completely fragmented and weakened the uniqueness and distinctiveness of Doha which was based on its past.

Globalization is more of a threat than opportunity for cities' urban identities, especially if they are not world heritage sites such as Doha. One of the major problems facing Doha is a rapidly disappearing of its unique urban identity and character due to the recent globalization waves. One of these waves reached the west bay of Doha, where, about 150 iconic high-rise towers have mushroomed during the last two decades. These steel and glass towers do not reflect the local, environmental and socio-cultural context that formed the essence of the city's urban identity (Figure 4).

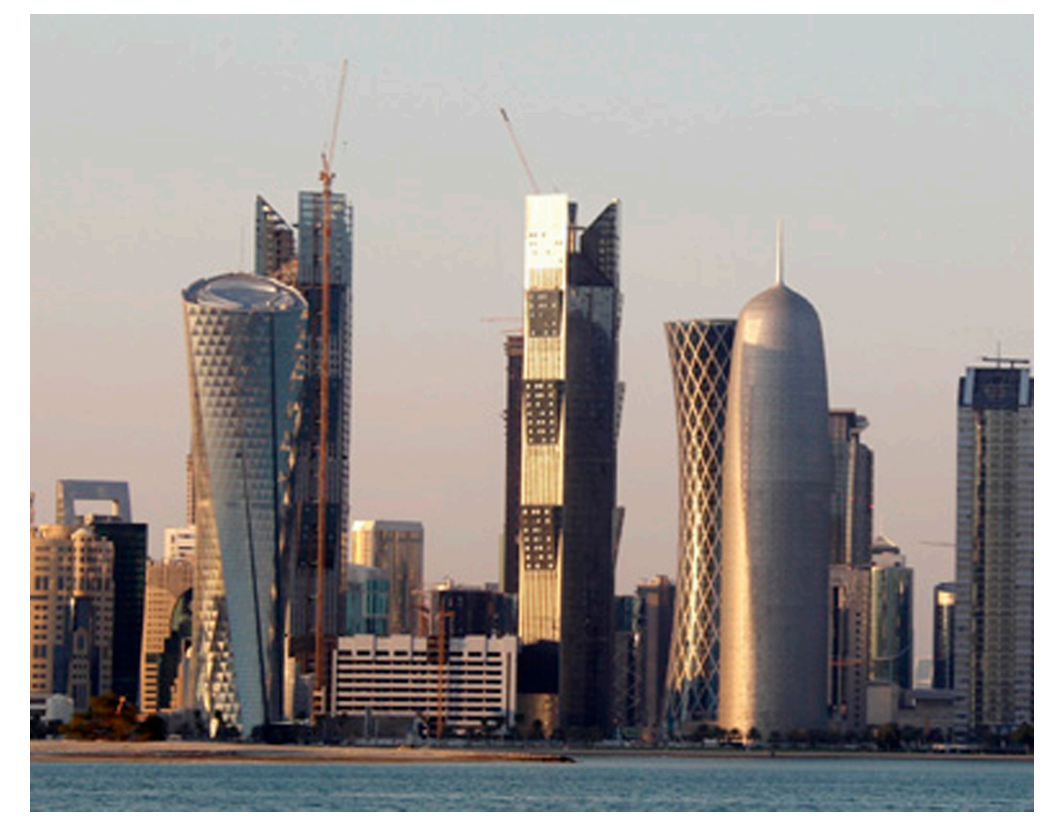

Figure 4. View of the mushrooming high rise towers in the West Bay area.

In order, to counterbalance the drift coming from the West bay a reconstruction of some chapters of the past identity of Doha started to see the light since early 2000. Rehabilitation of Souk Waqif is the first comprehensive project (Figure 5). It started in 2004 and was completed in 2010 by developing one of the most attractive heritage places in Doha. In 2008, a new project was followed; the Msheireb downtown project, which seeks to create a sustainable urban regeneration project as well as a new urban identity based on the past. Therefore, it is important to explore this project, in order to find out how urban regeneration can inject a new life in an old district while it can reinforce the city's identity inspired from its past.

Since this paper is mainly concerned with the physical aspects of urban identity, the fieldwork in Msheireb was mainly based on a comprehensive examination of the historic buildings in the heritage quarter. In this context, an extensive photographic survey was carried out inside and outside the buildings. In addition, a thorough exploration of books and journal articles was undertaken at Qatar University library. Furthermore, the Msheireb properties website offered a great opportunity for understanding the philosophy of the project, its different stages and all this supported by significant images of the past and present. 


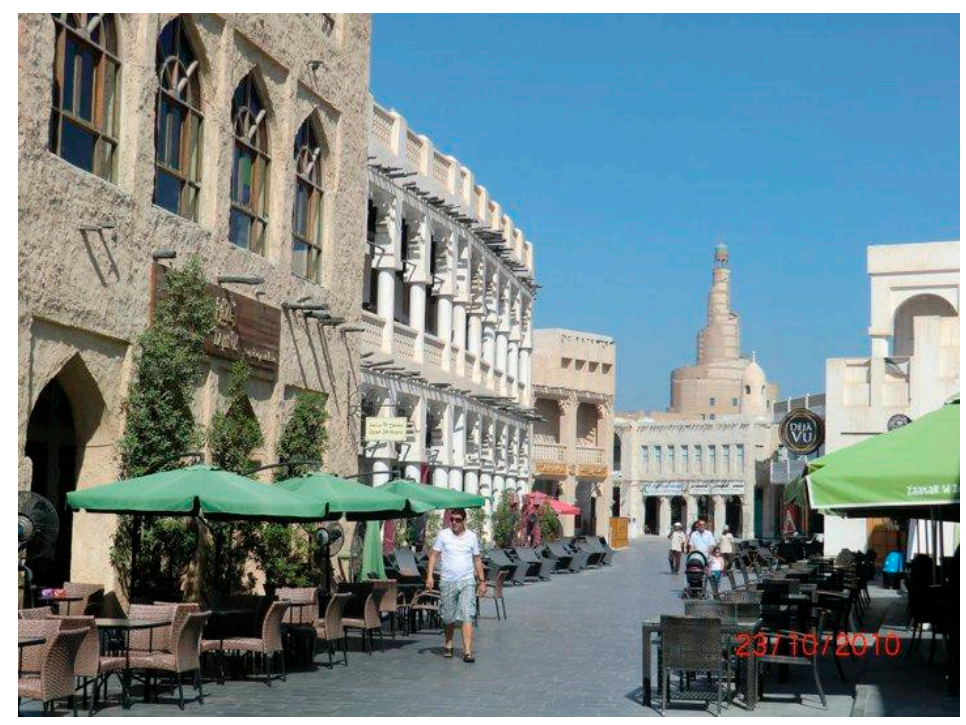

Figure 5. Souk Waqif; the restaurants area provides a bustling life day and night.

In order to further explore the heritage Quarter, since 2009, five visits with the students were conducted at the Msheireb site. These visits were undertaken within three research projects about old Doha and the history and heritage conservation courses. The researchers had the chance to visit the four heritage museums and the Baraha, take pictures and to ask questions to the main designers of the project. Architect Fatima Fawzi, from Msheireb Properties, guided the 5 tours and made a full presentation about the different stages of the project and the way it had been conducted. These five visits enabled the author to form a clear picture about the project and the heritage area.

\section{Msheireb Project; Regeneration and a New Urban Identity}

In 2008, the Msheireb project was launched over an area of 35 hectares, twenty times the size of the adjacent Souk Waqif (Figure 6). The aim of the project is to bring back the Qatari families to downtown Doha after their massive departure to the periphery during the 1950s and 60s. The intention is to foster and restore the idea of a community life inspired from the concept of traditional neighborhood "fareej". In terms of regeneration, this project aims to improve the environment and boost the economy of the area. In short, the following are the main objectives of the master plan: [47] (p. 133). "To promote a sustainable way of living within a compact city framework that reduces automobile usage, increases density and promotes public transport and mixed use;

- To renew a piece of city infrastructure so as to reduce its reliance on fossil fuel;

- To promote better integrated social communities at the heart of the city where locals and expatriate workers are walk able neighborhoods, public spaces and amenities;

- To modernize a piece of Qatar's capital city in ways that will resonate with local history and cultures."

In order to implement these objectives a number of modernization challenges are addressed in this master plan: [47] (p. 133).

- The short-term profit driven motives;

- Fragmented land ownership and its impact on the development pattern;

- Local climate and its impact on movement and urban form;

- The loss of community spirit and identity in the process of modernization;

- Image of the city-creation not transposition. 


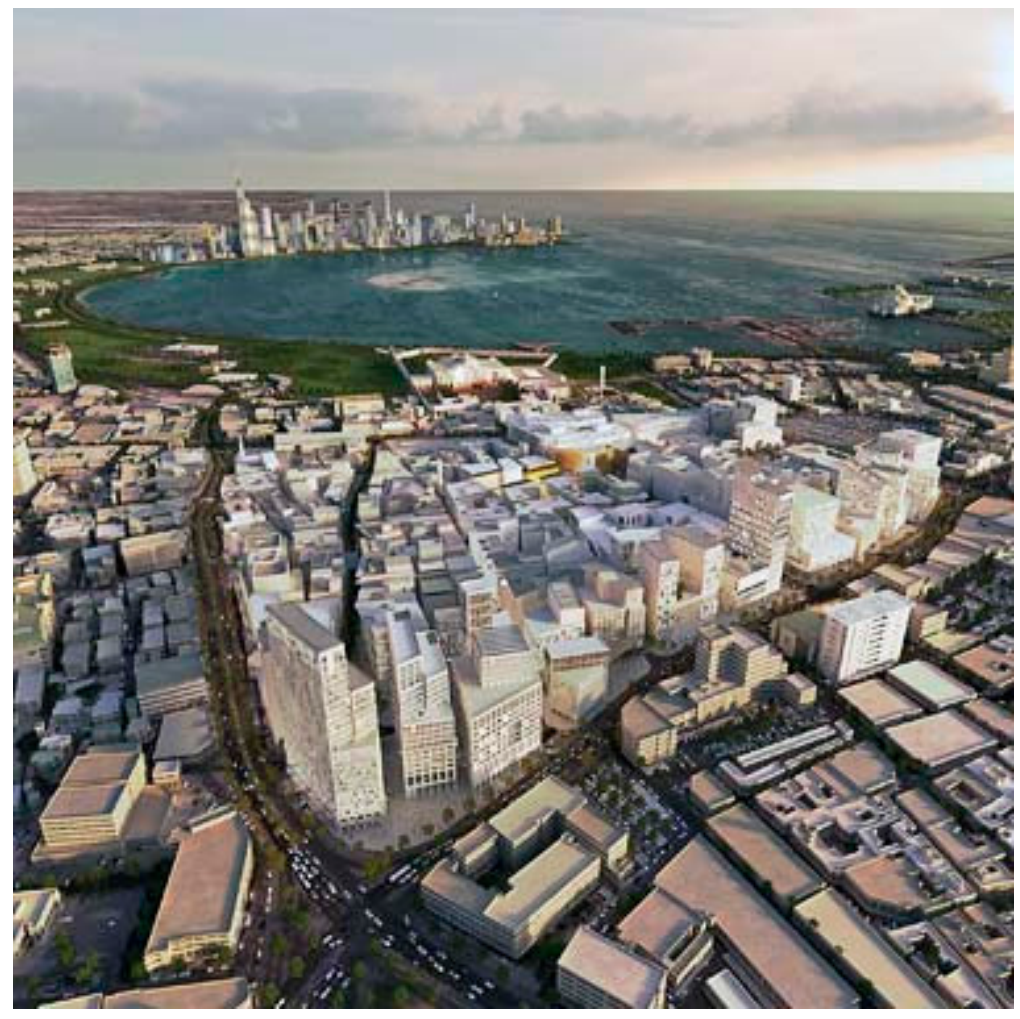

Figure 6. The Msheireb compact Development in Doha (http://mdd.msheireb.com/).

To implement these objectives; the master plan proposed a safe and a thriving residential/commercial center containing facilities and amenities within a walk able distance. In Msheireb, streets and neighborhoods form a compact urban pattern rather than being scattered each one in its own plot. The compact layout offers many advantages in terms of creating shaded streets that encourage inhabitants to walk. This compact urban pattern is inspired from the old neighborhoods (furjan), as a response to climatic and social considerations. In addition, it encourages the social interaction between neighbors that will eventually increase the sense of place and identity.

Msheireb is structured around five main districts that encourage social interaction (Figure 7). These districts consist of the Emiri Diwan Quarter, which will host the National Guard and other services supporting the Emiri Diwan. A second district, the Mixed-Use and Residential Quarter, adjacent to the commercial quarter. It contains the main plaza (Baraha) to be the main breathing element for the entire Msheireb area, residential buildings, offices and other dynamic activities. A third district, the Retail Quarter, is the largest district, which comprises the most luxurious spaces in the project and city of Doha. The fourth district, the Business Gateway Quarter, is a business-oriented quarter full of business opportunities and governmental representatives to facilitate future investments in the city. The heritage Quarter, which escaped miraculously from decimation, forms the fifth part and stands as the only physical witness of the past. It is the main gateway to Msheireb and acts as the catalyst to create a new urban identity for the entire district.

The need to establish a new urban identity and character for Msheireb was fundamental in creating a new image to the city. Instead of transcribing from the past, influences are inspired from studying the local built heritage. Lessons learnt from an examination of the historic districts in Doha and Al Wakra enabled the establishment of seven principles as a guide for the design of the master plan; timelessness, diversity and unity, form and geometry, aspect of home, aspect of street, designing for climate and elements of architecture [47] (p. 143). These principles intend to ease life for the future inhabitants while they provide them with a new urban identity inspired but not copied from the past. 


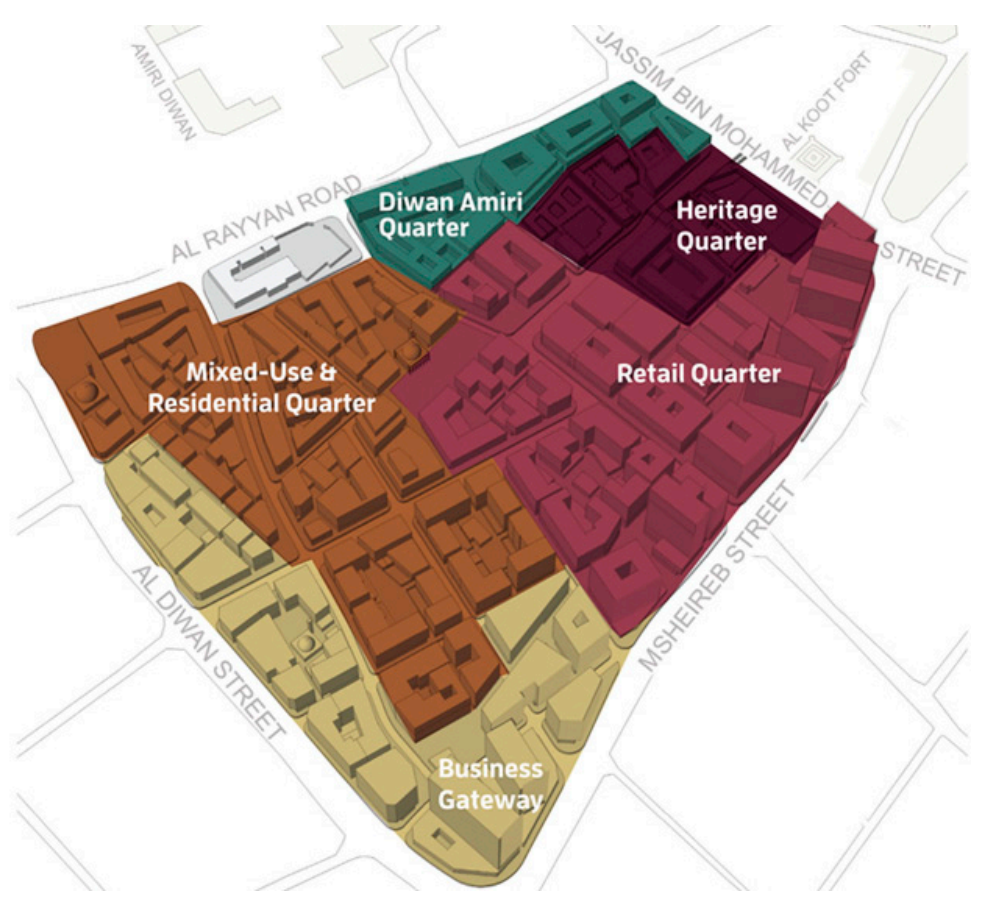

Figure 7. The five main districts in Msheireb (http://mdd.msheireb.com/).

The plan integrates a variety of activities with areas of specific character. Some areas are mainly residential while others are a mixture of retail and commercial space. The new fareej (district) incorporates a diversity of town homes within easy access to services and amenities. A key characteristic of the project is the vibrant public barahas (plazas), courtyards and gathering spaces that are extremely rare in Doha. To encourage walkability, cars are strategically placed underground in several basement levels. While work is still underway, the heritage quarter was completed and opened to public in April 2015.

\section{The Msheireb Heritage Quarter}

The heritage quarter is the only survivor heritage area in Msheireb, the quarter represents an area equivalent to $2 \%$ of the entire 35 ha site. The heritage quarter has two main roles; first, it functions as the main Msheireb's entrance, to welcome the local and global visitors from the adjacent Souq Waqif. Secondly, it provides a cultural trail to retrace Qatar's history before 1950.

The heritage quarter is strategically located between three significant heritage areas; Souk Waqif; the Amiri Diwan and Al Asmakh and forms the main gateway to the Msheireb district. The heritage quarter establishes a strong link with Souk Waqif visually and physically through two tunnels. Thus, it can extend the entertainment experience in Souk Waqif to the cultural environment of the four heritage museums (Figure 8).

The heritage quarter includes a large baraha used for Eid prayers, four significant old houses to keep traces and memories of the original site and a new mosque. These houses are Mohamed Bin Jassim Palace, Bin Jalmoud, Al Radwani and the Company houses. Except Radouani house, which still maintains the original structure, the three others have been reconstructed and were commodified to host various museums. In terms of regeneration, the heritage quarter has been regenerated as "a cultural trail" for local and global visitors (Figure 9).

In the heritage quarter, visitors first experience the authentic Radwani house built in 1947. This house delivers a visual presentation of the Qatari domestic life before oil era. Secondly, the Company House celebrates the creation of the first oil company in Doha. This house tells the story of how the State of Qatar shifted from pearling and fishing to oil based economy. Thirdly, Bin Jelmood 
house, exhibits the story of slavery in Qatar and the Gulf. The mission of this house is to pay respect towards the enslaved people who played a significant role in developing the Qatari nation. Finally, Mohamed Bin Jassim House, named after the son of the founder of modern Qatar, hosts a museum that reveals the memories of the past to present for future generations [48]. Therefore, in addition to Souk Waqif the heritage quarter has become a main tourist heritage attraction in Msheireb.

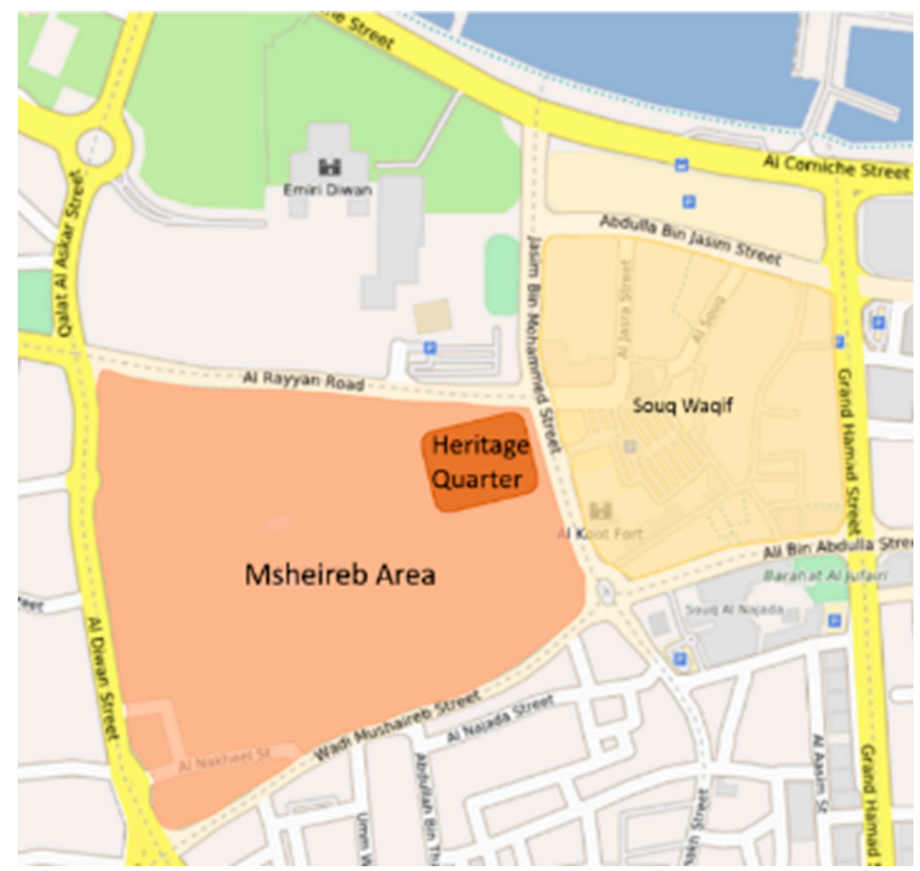

Figure 8. Location of the Heritage Quarter between Souk Waqif and the new Msheireb development. (Courtesy of Msheireb Properties).

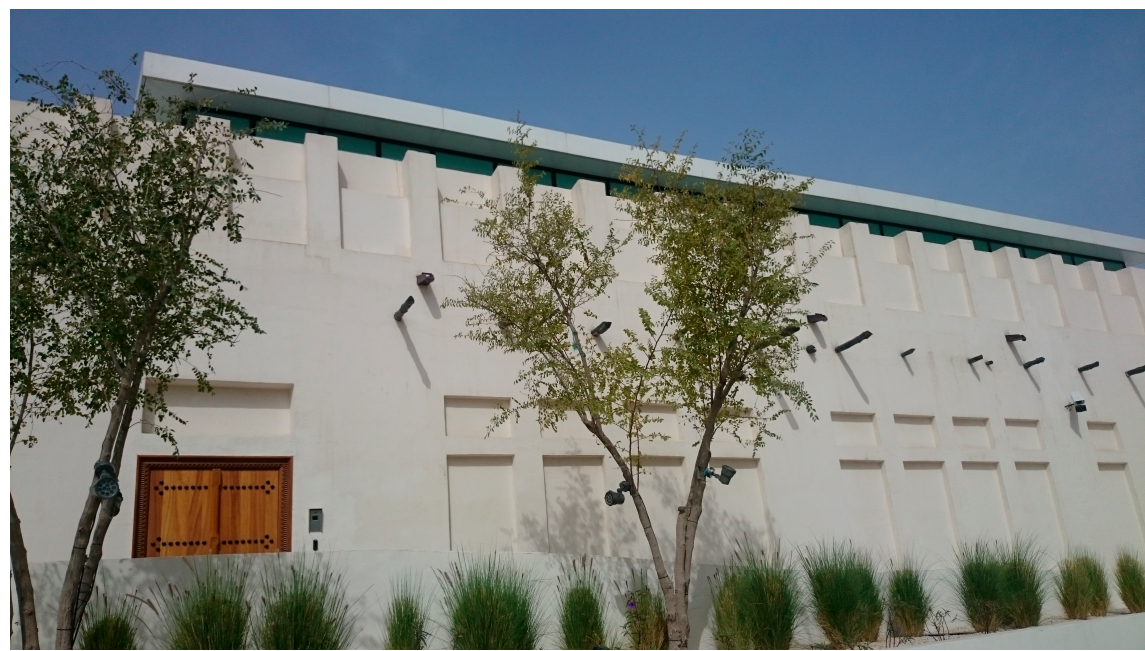

Figure 9. Rehabilitation of one of the four houses to accommodate a museum.

In Msheireb, the idea of creating a new image for Doha is generated from the site features, through a merging of the old and new streets. In addition, the mix of uses re-energizes the heritage quarter, located along a series of connected and memorable barahas with a new architectural language [46] (p. 141). While the heritage quarter represents a very small area; only $1 / 16$ from the entire area of Msheireb, in addition, it is hidden from three sides by the massive Msheireb 10-12 stories 
multi-use tower blocks; thus, it is unlikely to have a strong impact on the surroundings in enhancing the city's urban identity.

While the intention of Msheireb project is to create a sustainable quarter and new urban identity inspired from the past is highly innovative and significant, a number of other challenges can be identified. One of the major issues is the decimation of a complete historic quarter, causing the displacement of low-income 7000-9000 occupants. From an entire 35 hectares, only a small part containing four houses with an area of 2 hectares has survived. More care and sympathy could have been considered towards the original fareej where more houses could have been conserved, to ensure a stronger continuity with the past. The latter would have been reused to serve other functions, such as entertainment, retail and educational. In this sense, the link with the past would have been stronger.

The approach of Msheireb to establish a distinctive urban identity and character is not based on copying the past; it is a unique experience in reinterpreting the past in a contemporary way (Figure 10). The new urban identity draws from a thorough inspiration from the local traditional architecture. While this is significant, however the demolition of a large number of historic buildings did not help sustain a strong continuity with the history and past of the area. Furthermore, these four heritage houses while drawn in a sea of high, 10-12 stories tower blocks cannot alone represent the past.

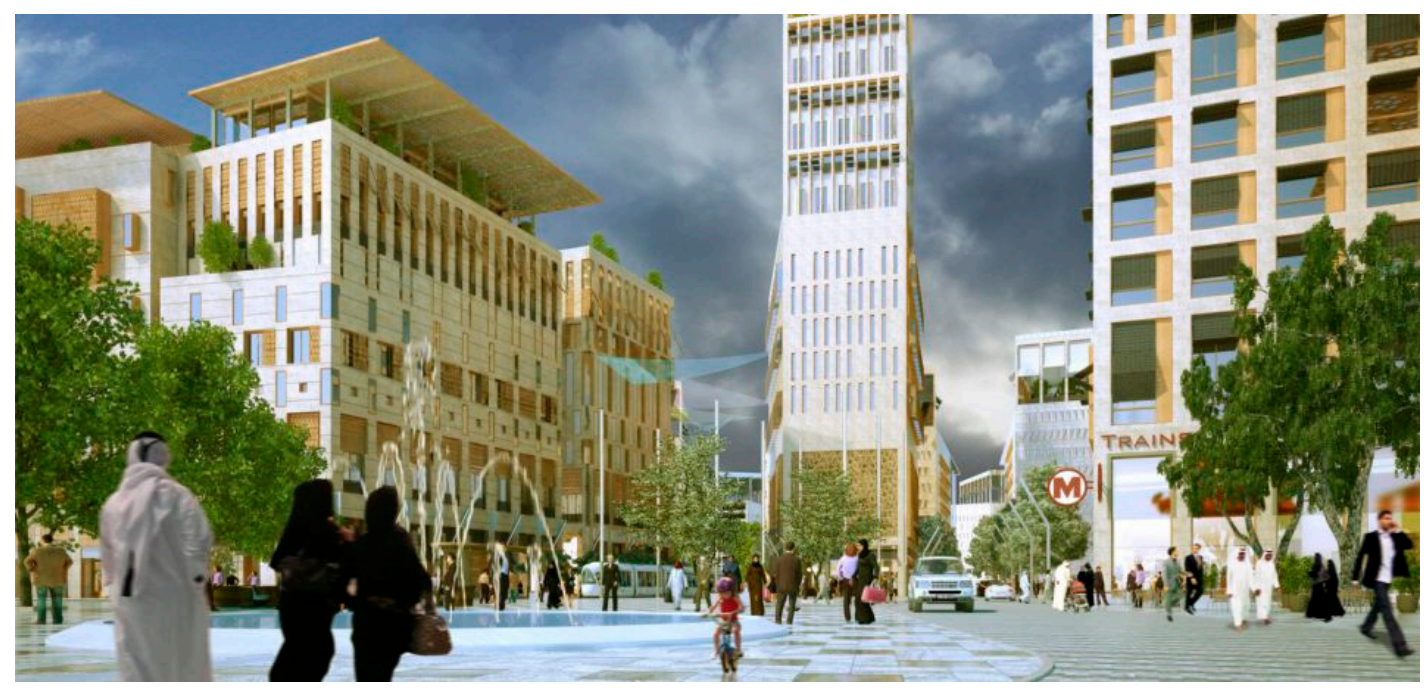

Figure 10. A new urban identity inspired from the Qatari traditional architecture (http://mdd.msheireb.com/).

Regarding, continuity, it is important to investigate whether imitating blindly traditional elements of the past in a new building is the best option to revive the past in the present city. In this way, Msheireb project explored an innovative way in using element of the past, by reinterpreting them and not copying them. This is an interesting way to undertake in new infill projects.

One of the main drawbacks of the project is the absence of a community participation in the project. Therefore, to achieve a local identity; community participation, should be reinforced. For example, the local inhabitants should have a say on which aspects of their cultural heritage need be conserved and sustained. In contrast, Duncan [49] and Clark [50] suggest that the physical environment can be modified through community participation in order to represent present selves and to present a new self, arguably a more active way of preserving place identity.

To reinforce the aspect of uniqueness, Msheireb tried to rehabilitate the heritage quarter, despite its limited area size with only four historic buildings. More cautious approach in the beginning would have allowed more historic buildings to survive and would have reinforced more its uniqueness. Concerning significance, designers argue that to achieve this cultural heritage should be preserved. In contrast, Msheireb showed another alternative of creating the new but inspired from the past. 
In Msheireb, compatibility also raises important issues. A clear contrast exists between the heritage quarter and the rest of Msheireb development. In addition, Msheireb lacked in creating a physical and visual fit with its adjacent districts such as Souk Waqif, Al Asmakh and Al Najada areas. The 10-12 stories buildings built on the edges of Msheireb created a line of high obstacles that block any visual corridors towards them. With a more cautious approach, compatibility could have been achieved with the surroundings and would have enabled a greater chance of attaining a stronger urban identity.

Cohesiveness concerns fostering a sense of community. Through its master plan based on the concept of Fareej, Msheireb aimed to create a sense of intimacy, homogeneity, or compactness in the built environment through physical designs. While it succeeded in achieving this within the limits of the Msheireb site, however it failed to expand this cohesiveness at the city level. The lack of continuity with the adjacent districts created more fragmentation of the city fabric thus weakened the city urban identity. Therefore, a greater sense of local identity of place may be achieved when promoting an overall coherent urban character or homogeneity.

\section{Conclusions}

An active way of accomplishing significance requires a strong, collective participation of residents. Residents can take part in a long-term process of making their environment significant even when no historically significant place exists in their community. By involving the community, "feeling pride or feeling good" about living in their city can grow as collective aspects of the community begin to be meaningful to their lives. Ultimately, this growth can lead to a greater sense of local identity for them.

Unlike what happened in Msheireb, when rehabilitation work is being planned, attention must be paid to see a historic urban center within the largest context of the city's historic landscape, the community, their needs and the impact on the immediate surroundings. Work should be part of an urban process designed to improve physical conditions and, where appropriate, regenerate the local economy. This can be achieved, by reinforcing local services and by injecting new activities responsive to the local inhabitants needs.

Urban identity adds quality to a project, it should therefore be a major component of urban planning tools, making it a must be in a city project. Therefore, there a need to stop decimation of old districts as it happened in Msheireb. To enhance the specific character of a city and to counter the standardization of spaces, which make them similar, it is required to conserve the elements that make a city unique based on its heritage legacy.

The challenge for architects, urban designers, planners, policymakers, legislators and all those involved in the future of cities and towns is to recognize the importance of urban identity in a global world and to enhance policies for its sustainability. Due to the rapid urban changes in historic cities, it is important that urban identity be monitored on a regular basis in order to understand the different trend changes that might compromise a city's uniqueness and distinctiveness.

Urban identity of a city stands on the dual characters of "individuality and uniqueness", encompassing both stability and dynamism. This is not just a question of the physical and implicit make-up but becomes a tool and reference for designing sustainable historic centers and districts. Regenerating the old as a catalyst to sustain a city's urban identity and life remains a central question for the historic cities of today. Urban regeneration of Msheireb has attempted to lay the ground and show the path through building a new urban identity inspired from the past. Such efforts need to first be assessed and evaluated and then decide whether to expand this experience to other historic cities.

As experienced in Msheireb, urban identity does not mean blind copying from the past but requires deep and thorough research and investigation of its principles. Identity cannot, however, be fossilized as a set of styles but should rather be considered as a dynamic process like life itself. The development of a new urban identity in Doha and other cities in the Gulf is a great challenge. More research is needed to find the best ways to regenerate the past as a catalyst for sustaining urban identity within the emerging global environments in the Gulf and worldwide. 
Conflicts of Interest: The authors declare no conflict of interest.

\section{References}

1. Carrion, F.M. The Historical Centre as an Object of Desire. City Time 2005, 1, 3.

2. Scheffler, N.; Kulikauskas, P.; Barreiro, F. Managing Urban Identities: Aim or Tool of Urban Regeneration? Academia Press: New York, NY, USA, 2009; pp. 9-13.

3. Tweed, C.; Southerland, M. Built cultural heritage and sustainable urban development. Landsc. Urban Plan. 2007, 83, 62-69. [CrossRef]

4. Evans, G. Measure for measure: Evaluating the evidence of culture's contribution to regeneration. Urban Stud. 2005, 42, 959-983. [CrossRef]

5. UN-HABITAT. State of the World's Cities 2010/2011: Bridging the Urban Divide; Earthscan: London, UK, 2011.

6. Jacobs, J. The Death and Life of Great American Cities; Modern Library: New York, NY, USA, 2011.

7. Lynch, K. What Time is This Place? MIT Press: Cambridge, MA, USA, 1972.

8. European Parliament. 1975. Available online: http://www.europarl.europa.eu/ftu/pdf/en/FTU_1.3.1.pdf (accessed on 25 July 2017).

9. Boussaa, D. Dubai: The Search for Identity. In People Places and Sustainability; Moser, G., Pol, E., Bernard, Y., Bonnes, M., Corraliza, J., Giuliani, V., Eds.; Hogrefe \& Huber Publishers: Göttingen, Germany, 2003; pp. 51-60.

10. Boussaa, D. Al Asmakh historic district in Doha, Qatar: From an urban slum to living heritage. J. Archit. Conserv. 2014, 20, 2-15. [CrossRef]

11. Boussaa, D. Cities in the Gulf; Rapid Urban Development and the Search for Identity in a Global World. In Population Growth and Rapid Urbanization in the Developing World; Benna, U.G., Garba, S.B., Eds.; IGI Global: Hershey, PA, USA, 2016; ISSN 2326-9103.

12. Lynch, K. The Image of the City; MIT Press: Cambridge, MA, USA, 1960.

13. Carta, M. L'armatura Culturale del Territorio Il Patrimonio Culturale Come Matrice di Dentita e Strumento per lo Svillupo; Franco Angeli: Milano, Italy, 1999.

14. Relph, E. Place and Placelessness; Pion: London, UK, 1976.

15. Butina-Watson, G.B.; Bentley, I. Identity by Design; Architectural Press: Oxford, UK, 2007.

16. Hague, C.; Jenkins, P. Place Identity, Planning and Participation; Routledge: London, UK, 2005; Available online: http:/ / www.icvbc.cnr.it/all\%202.pdf (accessed on 15 January 2017).

17. Norberg-Schulz, C. Genius Loci: Towards a Phenomenology of Architecture; Rizzoli: London, UK, 1980.

18. Halbwachs, M. On Collective Memory; University of Chicago Press: Chicago, IL, USA; London, UK, 1992.

19. Urry, J. Consuming Places; Routledge: London, UK; New York, NY, USA, 1995.

20. Nora, P. Realms of Memory 1-3; Columbia University Press: New York, NY, USA, 1996-1998.

21. Cheshmehzangi, A. Identity and public realm. Soc. Behav. Sci. 2012, 50, 307-317. [CrossRef]

22. Cheshmehzangi, A. Urban Identity as a Global Phenomenon: Hybridity and Contextualization of Urban Identities in the Social Environment. J. Hum. Behav. Soc. Environ. 2015, 25, 391-406. [CrossRef]

23. The Academy of Urbanism. Urban Identity, Learning from Place 2; Routledge: Oxon, UK, 2011.

24. Rossi, A. The Architecture of the City; Opposition Books: New York, NY, USA, 1982.

25. Schuster, J.; Davidson, M. Growth and the Loss of Regional Character. Places 1989, 6, 78-86.

26. Kim, J. Understanding Elements of Local Identity of Place: Physical vs. Personal-Social Attributes. In Proceedings of the 88th ACSA Annual Meeting Proceedings, Heterotopolis, La Verne Wells-Bowie, Los Angeles, CA, USA, 11-14 March 2000; pp. 451-455.

27. Lynch, K. A Theory of Good City Form; MIT Press: Cambridge, MA, USA, 1981.

28. Alexander, C.; Hajo, N.; Artemis, A.; Ingrid, K. A New Theory of Urban Design; Oxford University Press: New York, NY, USA, 1987.

29. Goldsteen, J.; Elliott, C. Designing America: Creating Urban Identity; Van Nostrand Reinhold: New York, NY, USA, 1993.

30. Kelbaugh, D. Common Place: Toward Neighborhood and Regional Design; University of Washington Press: Seattle, WA, USA, 1997.

31. Alexander, C. Sara Ishikawa, and Murray Silverstein. A Patfern Language; Oxford University Press: New York, NY, USA, 1977. 
32. Australia ICOMOS. The Burra Charter. ICOMOS: Burra, Australia, 1999. Available online: www.icomos. org/australia/burra.htm (accessed on 15 August 2017).

33. Jones, P.; Evans, J. Urban Regeneration in the UK; Sage: London, UK, 2013.

34. Roberts, P. The evolution and Purpose of Urban Regeneration. In Urban Regeneration: A Handbook; Roberts, P., Hykes, Eds.; Sage: London, UK, 2000; p. 17.

35. Graham, B.; Ashworth, G.; Tunbridge, J. A Geography of Heritage: Power, Culture and Economy (Hodder Arnold Publication); Routledge: London, UK, 2000.

36. Tunbridge, J.E.; Ashworth, G.J. Dissonant Heritage: The Management of the Past as a Resource in Conflict; Wiley: Hoboken, NJ, USA, 1996.

37. Al-Kholaifi, M.J. The Traditional Architecture in Qatar, National Council for Culture, Arts and Heritage; Museums and Antiquities Department: Doha, Qatar, 2006.

38. Adham, K. Rediscovering the Island: Doha's Urbanity form Pearls to Spectacle. In The Evolving Arab City: Tradition, Modernity and Urban Development; Elsheshtawy, Y., Ed.; Routledge: London, UK, 2008; pp. 218-257.

39. Jaidah, I.; Bourennane, M. The History of Qatari Architecture; Skira: Milan, Italy, 2009.

40. Radoine, H. Souk Waqif, Doha, Qatar, 2010 on Site Review Report. 2010. Available online: http:/ / archnet. org/system/publications/contents/8722/original/DTP101221.pdf?1396271815 (accessed on 10 June 2016).

41. Caton, S.; Ardalan, N. New Arab Urbanism, the Challenge to Sustainability and Culture in the Gulf; Harvard Kennedy School: Cambridge, MA, USA, 2010.

42. Salama, A.M.; Wiedmann, F. Demystifying Doha, on Architecture and Urbanism in an Emerging City; Ashgate: London, UK; New York, NY, USA, 2013.

43. Melhuish, C. Heritage E Renewal in Urban Doha; Urban Pamphleteer \# 4: London, UK, 2014.

44. Mazzetto, S.; Petruccioli, A. Methods and Techniques Used in Significant Restoration Projects in Qatar. Stud. Conserv. 2017, 1-12. [CrossRef]

45. Workshop on Modernization of Official Statistics in Qata. Available online: http://www.mdps.gov.qa (accessed on 1 December 2017).

46. Ministry of Information. Department of Tourism and Antiquities, Law No. 2 of 26.02.1980 on Antiquities; Ministry of Information: Doha, Qatar, 1980.

47. Law, R.; Underwood, K. Msheireb Heart of Doha: An Alternative Approach to Urbanism in the Gulf Region. Int. J. Islam. Archit. 2012, 1, 131-147. [CrossRef]

48. Gharib, R. Requalifying the Historic Centre of Doha: From Locality to Globalization. Conserv. Manag. Archaeol. Sites 2014, 16, 5-16. [CrossRef]

49. Duncan, J. Landscape Taste as a Symbol of Group Identity: A Westchester County Village. Geogr. Rev. 1973, 63, 334-355. [CrossRef]

50. Clark, K. (Ed.) Conservation Plans in Action, Proceedings of the Oxford Conference; English Heritage: London, UK, 1999.

(C) 2017 by the author. Licensee MDPI, Basel, Switzerland. This article is an open access article distributed under the terms and conditions of the Creative Commons Attribution (CC BY) license (http:/ / creativecommons.org/licenses/by/4.0/). 